\title{
Defining Team Effort Involved in Patient Care from the Primary Care Physician's Perspective
}

\author{
Andrew S. Hwang, MD MPH' , Steven J. Atlas, $M D M P H^{7}$, Johan Hong, $A B^{2}$, \\ Jeffrey M. Ashburner, $P h D, M P H^{7}$, Adrian H. Zai, MD, PhD, $\mathrm{MPH}^{3}$, Richard W. Grant, MD, $\mathrm{MPH}^{4}$, and \\ Clemens S. Hong, MD, MPH
}

'Division of General Internal Medicine, Department of Medicine, Massachusetts General Hospital, Boston, MA, USA; ${ }^{2}$ Stanford University School of Medicine, Stanford, CA, USA; ${ }^{3}$ Laboratory of Computer Science, Massachusetts General Hospital, Boston, MA, USA; ${ }^{4}$ Division of Research, Kaiser Permanente Northern California, Oakland, CA, USA; ${ }^{5}$ Los Angeles County Department of Health Services, Los Angeles, CA, USA.

BACKGROUND: A better understanding of the attributes of patients who require more effort to manage may improve risk adjustment approaches and lead to more efficient resource allocation, improved patient care and health outcomes, and reduced burnout in primary care clinicians.

OBJECTIVE: To identify and characterize high-effort patients from the physician's perspective.

DESIGN: Cohort study.

PARTICIPANTS: Ninety-nine primary care physicians in an academic primary care network.

MAIN MEASURES: From a list of 100 randomly selected patients in their panels, PCPs identified patients who required a high level of team-based effort and patients they considered complex. For high-effort patients, PCPs indicated which factors influenced their decision: medical/ care coordination, behavioral health, and/or socioeconomic factors. We examined differences in patient characteristics based on PCP-defined effort and complexity.

KEY RESULTS: Among 9594 eligible patients, PCPs classified 2277 (23.7\%) as high-effort and 2676 (27.9\%) as complex. Behavioral health issues were the major driver of effort in younger patients, while medical/care coordination issues predominated in older patients. Compared to low-effort patients, high-effort patients were significantly $(P<0.01$ for all) more likely to have higher rates of medical (e.g. $23.2 \%$ vs. $6.3 \%$ for diabetes) and behavioral health problems (e.g. $9.8 \%$ vs. $2.9 \%$ for substance use disorder), more frequent primary care visits (10.9 vs. 6.0 visits), and higher acute care utilization rates (25.8\% vs. $7.7 \%$ for emergency department [ED] visits and $15.0 \% \mathrm{vs}$. $3.9 \%$ for hospitalization). Almost one in five (18\%) patients who were considered high-effort were not deemed complex by the same PCPs.

CONCLUSIONS: Patients defined as high-effort by their primary care physicians, not all of whom were medically complex, appear to have a high burden of psychosocial issues that may not be accounted for in current chronic disease-focused risk adjustment approaches.

Electronic supplementary material The online version of this article (doi:10.1007/s11606-016-3897-6) contains supplementary material, which is available to authorized users.

Received March 16, 2016

Revised September 2, 2016

Accepted September 29, 2016

Published online October 21, 2016
KEY WORDS: primary care redesign; psychosocial; health services research; resource allocation; risk adjustment.

J Gen Intern Med 32(3):269-76

DOI: $10.1007 / \mathrm{s} 11606-016-3897-6$

() Society of General Internal Medicine 2016

\section{INTRODUCTION}

Provisions of the Affordable Care Act have accelerated primary care redesign and encouraged new reimbursement approaches. ${ }^{1}$ Redesign initiatives include a focus on multidisciplinary teams caring for primary care populations with increasing use of population-based reimbursement strategies. ${ }^{2}$ In this context, approaches to measuring patient-level primary care team effort are necessary to account for variation across primary care patient panels among clinicians and care teams. ${ }^{3,4}$

Prior studies have used measures of patient complexity to control for differences in the effort and resources needed to manage a given panel of patients. ${ }^{5-8}$ These predictive models and risk adjustment approaches focus predominately on the measures of medical complexity, including the number and severity of chronic conditions or prior healthcare utilization and cost. ${ }^{9-11}$ However, behavioral health, socioeconomic, and environmental factors that contribute to primary care team effort may not be adequately captured in current measures of patient complexity. $^{12-14}$

An ideal primary care risk adjustment measure would closely approximate the amount of clinician and primary care team effort needed to care for an individual patient or patient panel. Although most compensation models currently use relative value units (RVUs) as proxies for primary care effort, ${ }^{15}$ RVUs underestimate primary care clinician work. ${ }^{16,17}$ In particular, RVUbased reimbursement approaches capture only the effort related to face-to-face patient encounters. ${ }^{18}$ Given that a substantial and increasing proportion of primary care work occurs outside of office visits, ${ }^{19-21}$ new measures of effort also need to capture non-visit-based work. Patient-level factors also contribute to primary care team effort, but these factors are often difficult to identify from existing data sources. ${ }^{22}$ A better understanding of the attributes of patients who require more effort to manage may improve risk adjustment approaches, leading to more efficient 
resource allocation, improved patient care and health outcomes, and reduced burnout in primary care clinicians. ${ }^{23-28}$

Primary care physicians (PCPs) have a unique perspective on the relative level of effort required to care for patients in their panel, including both visit-based and non-visit-based work, as well as patients' psychosocial needs that affect primary care team effort. We previously evaluated a measure of patient complexity using physician qualitative assessments. ${ }^{13}$ In the current study, we sought to define cohorts of patients by physician-defined effort, characterize high-effort patients by domains of effort, and use electronically available data to identify patient-level factors that are important drivers of primary care team effort.

\section{METHODS}

\section{Participants and Setting}

We recruited staff PCPs from the Massachusetts General Primary Care Practice-Based Research Network. We linked all patients seen in our network in the previous 3 years to specific PCPs using a validated algorithm. ${ }^{29}$ We invited PCPs managing a panel of at least 100 patients in 2013 to review a list of 100 randomly selected patients using an electronic survey tool developed in REDCap version 5.9 (Vanderbilt University, Nashville, TN, USA). Participating PCPs received a gift card incentive of up to $\$ 250$.

\section{Variables}

After verifying that the patient was theirs, PCPs were asked, "How much effort does it take you and your team to care for this patient?" PCPs responded on a four-response scale (a lot of effort, moderate amount of effort, little effort, no effort). We categorized patients as high-effort (a lot or moderate amount of effort) or low-effort (little or no effort). For high-effort patients, PCPs indicated which factors from three effort domains influenced their decision (Table 1). We adopted these

Table 1 Effort Domains Associated with Physician-Identified HighEffort Patients

\begin{tabular}{|c|c|}
\hline Domain & Definition \\
\hline $\begin{array}{l}\text { Medical/care } \\
\text { coordination issues }\end{array}$ & $\begin{array}{l}\text { - The cognitive effort required to evaluate } \\
\text { and make the appropriate therapeutic } \\
\text { decisions } \\
\text { - The effort required to coordinate care } \\
\text { involving other providers and to make sure } \\
\text { that the medical system is working for the } \\
\text { patient }\end{array}$ \\
\hline Behavioral health issues & $\begin{array}{l}\text { - Psychiatric disorders that increase the } \\
\text { complexity of care (including addiction and } \\
\text { personality disorders) } \\
\text { - Patient behaviors that increase the } \\
\text { challenge of providing effective care (e.g. } \\
\text { suboptimal adherence) }\end{array}$ \\
\hline Socioeconomic issues & $\begin{array}{l}\text { - Influences outside the medical sphere that } \\
\text { increase the effort required to manage the } \\
\text { patient (e.g. home/work environment, } \\
\text { poverty/housing issues, or responsibilities } \\
\text { that interfere with clinical management) }\end{array}$ \\
\hline
\end{tabular}

domains from previously published concepts, ${ }^{13,} 30$ and modified them based on feedback from a primary care physician advisory group in our institution. We also asked PCPs, "In your view, do you consider this patient a 'complex patient'?" Since our goal was to compare physician-defined constructs of effort and complexity, we did not provide PCPs with a predetermined definition of effort or complexity. Based on PCPs' responses, we divided patients into four groups: 1) low-effort, not complex 2) high-effort, not complex (high-effort only), 3) low-effort, complex (complex only), and 4) high-effort, complex. To evaluate the impact of patient age on effort designation, we created eight age strata and assessed for changes in the prevalence of each effort domain.

PCP variables assessed included age, gender, time since graduation from medical school, years in practice at our institution, total outpatient visits in the previous 3 years, panel size, and whether they practiced at a community health center. We derived patient-related variables from data available in an electronic data repository over the preceding 3 years. ${ }^{31}$ Patient demographic variables included age, gender, self-reported race or ethnicity, language, and insurance status. We used outpatient scheduling data to identify the number of visits to the PCP and other practice providers, missed appointments ("noshow"), and number of different providers seen. We obtained data on admission and emergency department (ED) visits in the prior year, comorbid conditions, medication prescriptions, and laboratory results from the electronic medical record and billing data (using International Classification of Diseases, Ninth Revision [ICD-9] and Current Procedural Terminology [CPT] codes).

\section{Statistical Analyses}

We examined the relationship between effort and physician and patient panel characteristics using simple linear regression models, with the proportion of high-effort patients as a continuous outcome, and presented the summary statistics by tertiles of proportion of high-effort patients. We used logistic regression models using the general estimating equations approach (PROC GENMOD, SAS version 9.3; SAS Institute Inc., Cary, NC, USA) to compare the characteristics of patients who were 1) high-effort vs. low-effort, 2) high-effort only vs. complex only, and 3) high-effort only and complex only vs. high-effort, complex patients, while accounting for PCP-level clustering. We compared the prevalence of effort domains by age strata using a chi-square trend test. We also conducted multivariable regression analyses to identify predictors of patients being in each of the four groups. The institutional review board of Partners HealthCare approved our study.

\section{RESULTS}

Among eligible PCPs, $54 \%$ (99/182), representing $90 \%$ (17/ 19) of network practices, reviewed their patient lists. There were no statistically significant differences between 
participating and non-participating PCPs (Online Appendix 1). Of the 9900 patients provided to participating PCPs, PCPs reviewed 9832 patients and designated $238(2.4 \%)$ as not their patient. Among the remaining 9594 patients, PCPs classified $23.7 \%$ as high-effort (range 3.0-55.8 \%, SD $13.0 \%$ ) and $27.9 \%$ (range $5.0-64.0 \%$, SD $13.5 \%$ ) as complex (Table 2). Not all high-effort patients were deemed complex, and not all complex patients were deemed high-effort (Fig. 1).

Based on the proportion of patients designated as high-effort, there were no statistically significant differences between PCP characteristics, while differences in patient panel characteristics included mean age, insurance status, and number of clinic and PCP visits (Online Appendix 2). PCPs identified a mean of 1.7 effort domains associated with high-effort patients. Medical/ care coordination issues were most prevalent $(79.4 \%)$, followed by behavioral health $(59.7 \%)$ and socioeconomic issues $(31.5 \%)$. PCPs more frequently identified behavioral health issues in younger patients and medical/care coordination issues in older patients, while socioeconomic issues remained stable across age groups $(P<0.01$ for trends by decade) (Online Appendix 3).

\section{Unadjusted Analysis Comparing Patient Characteristics in the Different Effort/Complexity Groups}

Compared to low-effort patients, high-effort patients were older and were more likely to be female, reside in neighborhoods with lower median household income, be insured by Medicare or Medicaid, have a greater number of clinic/PCP visits, and see a greater number of different providers in their primary care practices. Compared to low-effort patients, higheffort patients were also significantly $(P<0.01)$ more likely to have medical (e.g. diabetes [23.2\% vs. $6.4 \%]$ ), psychiatric (e.g. bipolar disorder [4.5\% vs. $1.0 \%]$ ), and behavioral health (e.g. substance use disorder [9.8\% vs. $2.9 \%$ ]) comorbidities and have an ED visit $(25.8 \%$ vs. $7.7 \%)$ or hospitalization $(15.0 \%$ vs. $3.9 \%)$ in the prior year (Table 3 ).

Compared to patients designated as complex only, higheffort-only patients had a significantly $(P<0.05)$ greater number of clinic/PCP visits, saw a greater number of different providers in their primary care practices, and were prescribed fewer medications. The proportion of patients with ED visits was similar (14.7\% vs. $14.8 \%, p=0.61)$, but high-effort-only patients were less likely to have had a hospitalization (4.9\% vs. $9.3 \%, p=0.03$ ) in the past year (Table 4).
Compared to patients designated as high-effort only or complex only, patients who were both high-effort and complex were older and were more likely to reside in neighborhoods with lower median household income, have a higher number of clinic/PCP visits, and be prescribed a higher number of medications. In addition, compared to high-effort only and complex only patients, patients designated as both higheffort and complex were significantly $(P<0.05)$ more likely to have acute care utilization in the past year (e.g. hospitalizations [4.9\% and $9.3 \%$ vs. $17.2 \%]$ ), as well as medical (e.g. diabetes [11.8\% and $19.7 \%$ vs. $25.7 \%]$ ), psychiatric (e.g. depression [32.2\% and $31.5 \%$ vs. $48.9 \%$ ]), and behavioral health comorbidities (e.g. substance use disorder [4.4\% and $6.0 \%$ vs. $10.9 \%$ ]) (Table 4).

\section{Independent Predictors of the Different Effort/ Complexity Groups}

The high-effort only group was independently associated with being prescribed opiates and having increased primary care utilization, but fewer hospitalizations. The complex only group was independently associated with lower rates of ED and PCP visits despite being associated with measures of medical (e.g. being older and being prescribed more medications) and psychosocial complexity (e.g. being unmarried, and having high no-show rates). Lastly, the higheffort and complex group was associated not only with the aforementioned measures of medical and psychosocial complexity, but also with uncontrolled diabetes ( $\mathrm{HbA} 1 \mathrm{c}$ $>9 \%$ ), behavioral health comorbidities (e.g. substance use disorder, and anxiety/depression), as well as higher rates of ED and PCP visits (Table 5).

\section{DISCUSSION}

In this study, we presented a new measure of primary care team effort based on PCPs' qualitative assessment of their patients. We described the characteristics of patients whom PCPs deemed to require a high level of effort to manage, assessed the relationship between PCP-defined primary care team effort and patient complexity, and identified characteristics that were independently associated with high primary care team effort. Our results suggest that PCP-defined effort represents a unique construct that is interrelated with, but distinct from, complexity.

Within a large academic healthcare system, PCPs designated a quarter of their patients as high-effort, and reported

Table 2 PCP-Reported Effort and Complexity

\begin{tabular}{|c|c|c|c|c|}
\hline Level of effort & & Overall $(N=9594)$ & Complex $(N=6918)$ & $\begin{array}{l}\text { Not complex } \\
(N=2676)\end{array}$ \\
\hline High effort $(N=2277)$ & $\begin{array}{l}\text { A lot } \\
\text { A moderate amount }\end{array}$ & $\begin{array}{l}363(3.8 \%) \\
1914(19.9 \%)\end{array}$ & $\begin{array}{l}355(13.3 \%) \\
1515(56.6 \%)\end{array}$ & $\begin{array}{l}8(0.1 \%) \\
399(5.8 \%)\end{array}$ \\
\hline Low effort $(N=7317)$ & $\begin{array}{l}\text { A little } \\
\text { None }\end{array}$ & $\begin{array}{l}4858(50.6 \%) \\
2459(25.6 \%)\end{array}$ & $\begin{array}{l}764(28.6 \%) \\
42(1.6 \%)\end{array}$ & $\begin{array}{l}4094(59.2 \%) \\
2417(34.9 \%)\end{array}$ \\
\hline
\end{tabular}




\section{Total Study Population, $\mathbf{N}=9594$}

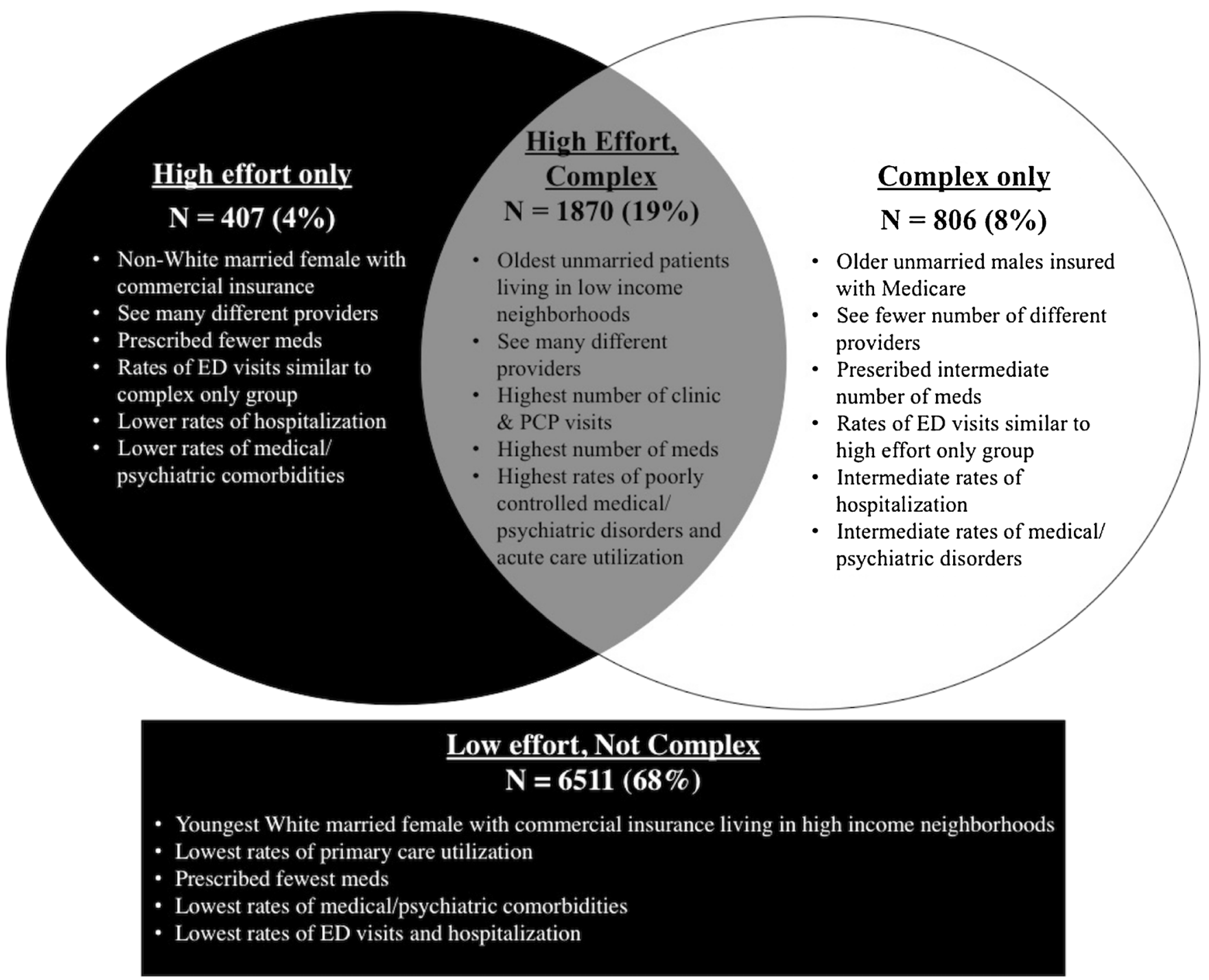

Figure 1 Four different patient groups based on PCP-defined effort and complexity.

medical/care coordination, behavioral health, and social factors as contributors to primary care team effort. Psychosocial factors, which are typically not incorporated into traditional risk adjustment and complexity measurement approaches, appeared to weigh heavily in PCPs' assessment of primary care team effort, with two- to sixfold higher prevalence of behavioral health problems in high-effort patients.

We previously examined medical, behavioral health, and social factors associated with PCP-defined complexity, and found that it was distinct from traditional comorbidity-based measures of complexity. ${ }^{13}$ However, measures of complexity, including our measure of PCP-defined complexity, ${ }^{32}$ do not always correlate with the effort required to care for patients. For example, a medically complex patient who receives extensive support from a caregiver at home or from a multidisciplinary specialty care team may not require a lot of effort from a primary care team. Conversely, a patient with few medical comorbidities might have significant behavioral health or social issues that require extensive attention from the primary care team. In our study, almost one in five (18\%) patients who were considered high-effort were not deemed complex by the same PCPs.

Characterizing our cohort by PCP-defined effort and complexity generated four different patient groups: 1) low-effort, not complex; 2) high-effort, not complex (high-effort only); 3) low-effort, complex (complex only); and 4) high-effort, complex. Although each group likely represents a heterogeneous group of individuals, a conceptual framework developed from PCP-defined effort and complexity (Fig. 1) may be useful for health systems attempting to better allocate resources and redesign primary care to meet the quadruple aim of improving clinical care, patient care experience, provider work satisfaction, and costs. ${ }^{33}$

From a population perspective, high-effort complex patients represent a group of individuals who have both medical and psychosocial complexity that demands significant effort from 
Table 3 Characteristics of Physician-Defined High-Effort vs. LowEffort Patients

\begin{tabular}{|c|c|c|c|}
\hline \multirow[t]{2}{*}{ Variable } & \multicolumn{2}{|l|}{ Level of effort } & \multirow{2}{*}{$\begin{array}{l}P \\
\text { value }\end{array}$} \\
\hline & $\begin{array}{l}\text { Lower-effort } \\
\text { patients } \\
(N=7317)\end{array}$ & $\begin{array}{l}\text { High-effort } \\
\text { patients } \\
(N=2277)\end{array}$ & \\
\hline \multicolumn{4}{|l|}{ Demographics } \\
\hline Mean age (years) & 51.2 & 60.9 & $<0.01$ \\
\hline Women (\%) & 59.8 & 64.7 & $<0.01$ \\
\hline Nonwhite (\%) & 22.8 & 22.5 & 0.39 \\
\hline \multicolumn{4}{|l|}{ Insurance status (\%) } \\
\hline Commercial & 72.7 & 44.1 & $<0.01$ \\
\hline Medicare & 15.5 & 40.1 & $<0.01$ \\
\hline Medicaid & 8.7 & 13.7 & $<0.01$ \\
\hline Uninsured & 3.1 & 2.2 & 0.03 \\
\hline $\begin{array}{l}\text { Median household } \\
\text { income }(\$)^{*}\end{array}$ & 77,579 & 68,716 & $<0.01$ \\
\hline $\begin{array}{l}\text { Did not graduate from } \\
\text { high school }(\%)^{*}\end{array}$ & 11.1 & 14.1 & $<0.01$ \\
\hline Unmarried (\%) & 42.5 & 53.8 & $<0.01$ \\
\hline \multicolumn{4}{|l|}{ Primary care utilization } \\
\hline Mean clinic visits $(n)$ & 6.0 & 10.9 & $<0.01$ \\
\hline Mean PCP visits $(n)$ & 4.2 & 8.3 & $<0.01$ \\
\hline $\begin{array}{l}\text { "No-show" rate }>25 \% \\
(\%)\end{array}$ & 6.7 & 8.7 & 0.01 \\
\hline Mean provider seen $(n)$ & 2.1 & 2.8 & $<0.01$ \\
\hline Mean prescribed & 5.4 & 11.2 & $<0.01$ \\
\hline medications $(n)$ & & & \\
\hline \multicolumn{4}{|l|}{ Laboratory results (\%) } \\
\hline Hemoglobin A1c $>9 \%$ & 1.2 & 6.2 & $<0.01$ \\
\hline $\begin{array}{l}\text { International normalized } \\
\text { ratio }>3.5\end{array}$ & 1.0 & 5.3 & $<0.01$ \\
\hline \multirow{2}{*}{\multicolumn{4}{|c|}{ Clinical encounters $(\%)$}} \\
\hline & & & \\
\hline $\begin{array}{l}\text { Emergency department } \\
\text { visits }\end{array}$ & 7.7 & 25.8 & $<0.01$ \\
\hline Hospitalizations & 3.9 & 15.0 & $<0.01$ \\
\hline \multicolumn{4}{|l|}{ Diagnoses $(\%)$} \\
\hline Bipolar disorder & 1.5 & 6.0 & $<0.01$ \\
\hline Alcohol-related & 4.1 & 9.7 & $<0.01$ \\
\hline Atrial fibrillation & 2.8 & 11.9 & $<0.01$ \\
\hline Diabetes & 6.3 & 23.2 & $<0.01$ \\
\hline $\begin{array}{l}\text { Post-traumatic stress } \\
\text { disorder }\end{array}$ & 1.2 & 5.7 & $<0.01$ \\
\hline Psychosis & 2.5 & 11.6 & $<0.01$ \\
\hline Personality disorder & 0.4 & 3.1 & $<0.01$ \\
\hline Substance use disorder & 2.9 & 9.8 & $<0.01$ \\
\hline Depression & 20.5 & 45.9 & $<0.01$ \\
\hline Chronic pain & 1.7 & 11.1 & $<0.01$ \\
\hline Anxiety & 19.8 & 39.6 & $<0.01$ \\
\hline \multicolumn{4}{|l|}{ Medications (\%) } \\
\hline Benzodiazepines & 32.4 & 55.4 & $<0.01$ \\
\hline Opiates & 24.6 & 35.4 & $<0.01$ \\
\hline Selective serotonin & 0.7 & 3.6 & $<0.01$ \\
\hline \multicolumn{4}{|l|}{ reuptake inhibitors } \\
\hline Antipsychotics & 0.1 & 0.6 & $<0.01$ \\
\hline Smoking cessation & 2.8 & 8.7 & $<0.01$ \\
\hline
\end{tabular}

*Based on census block group data

primary care teams. These individuals have coexisting chronic medical and behavioral health issues and unmet social needs that drive high rates of acute care utilization and make them harder to manage. They represent an ideal target for care management programs that employ multidisciplinary teams to address not only patients' medical comorbidities, but also their complex psychosocial needs. ${ }^{34}$

The high-effort only group represents the "worried well." 35 These individuals have fewer or better-managed chronic medical conditions and a lower rate of hospitalization than complex patients, but present frequently to the clinic and the $\mathrm{ED}$, are more likely to be prescribed opiates, and see many different providers. Involvement from a greater number of providers increases the potential for care fragmentation, which leads to increased primary care team effort in care coordination activities. This highlights the importance of accounting for non-visit-based work (e.g. frequency of electronic communications with patients and other providers) in assessing primary care team effort. Primary care teams may want to ensure same-day or next-day access and focus on improving continuity of care through co-management of patients with a midlevel provider. ${ }^{36}$ Given the high prevalence of coexisting behavioral health comorbidities among patients receiving opioids for chronic non-cancer pain, ${ }^{37,} 38$ approaches that promote close collaboration with mental health and addiction specialists will also be important for this population. ${ }^{39,40}$

Conversely, the complex only group comprises patients with increased medical complexity as evidenced by older age, higher number of prescribed medications, and multiple behavioral health and social issues. However, these complex issues do not drive frequent acute care utilization or primary care team effort in the ways the data might predict. One potential explanation for this discrepancy is that, unlike the high-effort complex group, where medical and psychosocial comorbidities coexist, this group is composed of two distinct subgroups: medically complex older individuals with multiple well-controlled chronic conditions, and psychosocially complex younger, healthier individuals who are uninsured and have high no-show rates.

Improved risk stratification models are needed to identify high-effort patients, ${ }^{41}$ because traditional diagnosis-based measures do not fully account for patient complexity or the level of primary care effort required to manage patients. ${ }^{42}$ The fact that PCPs in our study did not consider all medically complex patients, such as those with a greater burden of chronic diseases and higher rates of hospitalization, as higheffort patients supports the idea that primary care risk adjustment models must take into account demographic and psychosocial factors as well as an assessment of available practice resources. PCPs' unique knowledge of their patients, their teams, and their practice assets allows them to account for some of these factors. However, it is time-consuming and impractical for PCPs to review their entire panel of patients, and incorporating PCP review into a risk adjustment approach would introduce the possibility of gaming the system. A better understanding of physician-reported primary care team effort will help strengthen risk adjustment approaches and allow us to better use quantitative data sets to distinguish between highand low-effort patients. This will become increasingly important as we move towards risk-adjusted population-based reimbursement strategies.

Our results show that factors contributing to primary care team effort changed with a patient's age. Older patients were more likely to be considered high-effort due to medical or care coordination issues, while younger patients posed challenges 
Table 4 Characteristics of High-Effort Patients Versus Complex Patients

\begin{tabular}{|c|c|c|c|c|c|}
\hline$\overline{\text { Variable }}$ & $\begin{array}{l}\text { Low-effort \& not } \\
\text { complex }(N=6511)\end{array}$ & $\begin{array}{l}\text { High-effort } \\
\text { only }(N=407)\end{array}$ & $\begin{array}{l}\text { Complex only } \\
(N=806)\end{array}$ & $\begin{array}{l}\text { High-effort \& complex } \\
(N=1870)\end{array}$ & $P$ value ${ }^{*}$ \\
\hline \multicolumn{6}{|l|}{ Patient demographics } \\
\hline Mean age (years) & $50.0^{\S}$ & $54.2^{\S}$ & $60.9^{\ddagger}$ & 62.3 & 0.50 \\
\hline Women $(\%)$ & $60.1^{\S}$ & 67.3 & $57.8^{\S}$ & 64.2 & 0.16 \\
\hline Nonwhite (\%) & 22.9 & 26.8 & $19.1^{\ddagger}$ & 21.9 & 0.13 \\
\hline \multicolumn{6}{|l|}{ Insurance status $(\%)$} \\
\hline Commercial & $75.3^{\S}$ & $62.9^{\S}$ & $51.5^{\S}$ & 40.0 & 0.13 \\
\hline Medicare & $13.1^{\S}$ & $23.1^{\S}$ & $35.0^{\S}$ & 43.7 & 0.19 \\
\hline Medicaid & $8.6^{\S}$ & 11.3 & $10.2^{\ddagger}$ & 14.2 & 0.76 \\
\hline Uninsured & $3.0^{+}$ & 2.7 & 3.4 & 2.1 & 0.48 \\
\hline Median household income $(\$)^{\dagger}$ & $78093^{\S}$ & $75073^{\S}$ & $73280^{*}$ & 67327 & 0.23 \\
\hline Did not graduate from high school $(\%)^{\dagger}$ & $11.0^{\S}$ & $12.8^{+}$ & $11.8^{\frac{1}{4}}$ & 14.4 & 0.38 \\
\hline Unmarried $(\%)$ & $41.7^{\S}$ & $40.8^{\S}$ & $49.3^{\S}$ & 56.6 & $<0.01$ \\
\hline \multicolumn{6}{|l|}{ Primary care utilization } \\
\hline Mean clinic visits $(n)$ & $5.7^{\S}$ & $8.4^{\S}$ & $8.3^{\S}$ & 11.4 & $<0.01$ \\
\hline Mean PCP visits $(n)$ & $4.0^{\S}$ & $5.8^{\S}$ & $5.8^{\S}$ & 8.8 & $<0.01$ \\
\hline "No-show" rate $>25 \%(\%)$ & $6.6^{\S}$ & 7.3 & 8.1 & 9.0 & 0.40 \\
\hline Mean provider seen $(n)$ & $2.1^{\S}$ & 2.7 & $2.3^{\S}$ & 2.8 & $<0.01$ \\
\hline Mean prescribed medications $(n)$ & $4.9^{\S}$ & $7.7^{\S}$ & $9.0^{\S}$ & 12.0 & 0.04 \\
\hline \multicolumn{6}{|l|}{ Laboratory results $(\%)$} \\
\hline Hemoglobin A1c >9 \% & $0.8^{\S}$ & $3.0^{\ddagger}$ & $4.7^{\S}$ & 6.8 & 0.06 \\
\hline International normalized ratio $>3.5$ & $0.6^{\S}$ & $0.7^{\ddagger}$ & 4.1 & 6.3 & $<0.01$ \\
\hline Substance use disorder & $1.0^{\S}$ & $3.0^{\S}$ & $4.7^{\S}$ & 11.7 & 0.07 \\
\hline \multicolumn{6}{|l|}{ Clinical encounters $(\%)$} \\
\hline Emergency department visits & $6.9^{\S}$ & $14.7^{\S}$ & $14.8^{\S}$ & 28.2 & 0.61 \\
\hline Hospitalizations & $3.3^{\S}$ & $4.9^{\S}$ & $9.3^{\S}$ & 17.2 & 0.03 \\
\hline \multicolumn{6}{|l|}{ Diagnoses $(\%)$} \\
\hline Bipolar disorder & $1.2^{\S}$ & $2.0^{\S}$ & $4.3^{*}$ & 6.8 & 0.08 \\
\hline Alcohol-related & $3.6^{\S}$ & $5.9^{\ddagger}$ & $8.4^{*}$ & 10.5 & 0.23 \\
\hline Atrial fibrillation & $2.1^{\S}$ & $3.9^{\S}$ & $8.7^{\S}$ & 13.6 & 0.06 \\
\hline Diabetes & $4.7^{\S}$ & $11.8^{\S}$ & $19.7^{\S}$ & 25.7 & 0.10 \\
\hline Post-traumatic stress disorder & $1.0^{\S}$ & $3.4^{\dagger}$ & $2.6^{\S}$ & 6.2 & 0.21 \\
\hline Psychosis & $2.0^{\S}$ & $3.0^{\S}$ & $7.0^{\S}$ & 13.4 & $<0.01$ \\
\hline Personality disorder & $0.4^{\S}$ & 1.7 & $0.7^{\S}$ & 3.4 & 0.59 \\
\hline Substance use disorder & $2.6^{\S}$ & $4.4^{\S}$ & $6.0^{\S}$ & 10.9 & 0.48 \\
\hline Depression & $19.1^{\S}$ & $32.2^{\S}$ & $31.5^{\S}$ & 48.9 & 0.40 \\
\hline Chronic pain & $1.4^{\S}$ & $4.7^{\S}$ & $4.2^{\S}$ & 12.5 & 0.46 \\
\hline Anxiety & $19.1^{\S}$ & $30.7^{\S}$ & $25.7^{\S}$ & 41.5 & 0.70 \\
\hline \multicolumn{6}{|l|}{ Medications (\%) } \\
\hline Benzodiazepines & $30.6^{\S}$ & $45.2^{\S}$ & $46.4^{\S}$ & 57.6 & 0.72 \\
\hline Opiates & $23.6^{\S}$ & $37.6^{\S}$ & $33.0^{\S}$ & 47.1 & 0.39 \\
\hline Selective serotonin reuptake inhibitors & $0.5^{\S}$ & $1.0^{\S}$ & $1.9^{\ddagger}$ & 4.2 & 0.05 \\
\hline Antipsychotics & $0.1^{\S}$ & 0.3 & 0.5 & 0.6 & 0.52 \\
\hline Smoking cessation & $2.4^{\S}$ & $3.9^{\S}$ & $5.5^{\S}$ & 9.8 & 0.19 \\
\hline
\end{tabular}

*High-effort only vs. complex only

'Based on census block group data

${ }^{t} P<0.05$ for high-effort and complex vs. high-effort only, complex only, or low-effort and not complex

${ }^{s_{P}}<0.01$ for high-effort and complex vs. high-effort only, complex only, or low-effort and not complex

related to behavioral health issues. For PCPs who have closed and aging patient panels, investment in and use of an intensive care management team that can perform care coordination activities and help patients manage multiple chronic conditions will likely be most valuable. ${ }^{43}$ For PCPs with mostly younger patients, better integration of primary care and behavioral health teams may be more effective. ${ }^{44,45}$

For this study, we primarily used electronically available patient data, which allowed us to construct a conceptual framework for effort and complexity in primary care at the population level, but did not provide enough granularity to further segment patients into clinically actionable subgroups. Although our network includes a variety of practice types, including community health centers, findings from a single health system may not be generalizable to other primary care networks. PCPs' assessments were cross-sectional in nature, while domains that drive primary care team effort and patient complexity are likely to fluctuate over time. Utilizing new data sources to monitor not only patients' clinical status, but also changes in patients' social and behavioral determinants of health, will be important. ${ }^{46}$ Although PCPs incorporate knowledge of their practice and team assets in their assessments of primary care team effort, their assessment may be incomplete. Therefore, repeat surveys and in-depth qualitative work with PCPs in other practice settings may help broaden our understanding of PCPs' perception of patient complexity and effort. At this time, there are no standardized or validated methods of defining primary care effort. Further research is needed to identify important determinants of primary care team effort (e.g. specific combinations of chronic diseases and medications) and to develop new approaches for measuring primary care team effort that encompass non-visit-based work, primary care team and practice assets, and relevant patient characteristics. 
Table 5 Independent Predictors of Four Different Effort and Complexity Patient Groups

\begin{tabular}{|c|c|c|c|c|}
\hline \multirow[t]{2}{*}{ Variables } & \multicolumn{4}{|l|}{ Adjusted OR [95 \% CI] } \\
\hline & Low-effort \& not complex & High-effort only & Complex only & High-effort \& complex \\
\hline \multicolumn{5}{|l|}{ Patient demographics } \\
\hline Age & $0.98[0.97-0.98]$ & $1.01[1.00-1.02]$ & $1.02[1.01-1.03]$ & $1.02[1.01-1.03]$ \\
\hline \multicolumn{5}{|l|}{ Gender } \\
\hline Male & Ref & Ref & Ref & Ref \\
\hline Female & $0.98[0.86-1.11]$ & $1.05[0.80-1.39]$ & $0.85[0.71-1.02]$ & $1.06[0.93-1.21]$ \\
\hline \multicolumn{5}{|l|}{ Race } \\
\hline White & Ref & Ref & Ref & Ref \\
\hline Nonwhite & $0.99[0.84-1.18]$ & $1.04[0.74-1.45]$ & $0.91[0.74-1.11]$ & $1.04[0.88-1.23]$ \\
\hline \multicolumn{5}{|l|}{ Insurance status } \\
\hline Commercial & Ref & Ref & Ref & Ref \\
\hline Medicare & $0.62[0.52-0.73]$ & $1.14[0.82-1.59]$ & $1.08[0.87-1.35]$ & $1.52[1.25-1.83]$ \\
\hline Medicaid & $0.75[0.60-0.93]$ & $1.11[0.75-1.62]$ & $1.14[0.87-1.49]$ & $1.39[1.11-1.75]$ \\
\hline Uninsured & $1.27[0.58-1.07]$ & $1.18[0.68-2.05]$ & $1.46[1.04-2.07]$ & $0.97[0.63-1.48]$ \\
\hline Median household income* & $1.00[1.00-1.00]$ & $1.00[1.00-1.00]$ & $1.00[1.00-1.00]$ & $1.00[1.00-1.00]$ \\
\hline Did not graduate from high school* & $0.99[0.98-1.00]$ & $1.00[0.99-1.01]$ & $1.00[0.99-1.01]$ & $1.00[0.99-1.01]$ \\
\hline \multicolumn{5}{|l|}{ Marital status } \\
\hline Married & Ref & Ref & Ref & Ref \\
\hline Unmarried & $0.75[0.67-0.84]$ & $0.83[0.68-1.01]$ & $1.23[1.07-1.41]$ & $1.38[1.22-1.56]$ \\
\hline \multicolumn{5}{|l|}{ Primary care utilization } \\
\hline Number of clinic visits & $0.98[0.96-1.01]$ & $1.04[1.00-1.08]$ & $1.01[0.99-1.04]$ & $1.02[0.99-1.04]$ \\
\hline Number of PCP visits & $0.90[0.87-0.93]$ & $0.98[0.95-1.02]$ & $0.96[0.93-0.99]$ & $1.13[1.09-1.16]$ \\
\hline "No-show" rate & $0.16[0.09-0.27]$ & $1.02[0.30-3.50]$ & $2.18[1.11-4.23]$ & $8.76[4.75-16.18]$ \\
\hline Number of providers seen & $0.99[0.94-1.04]$ & $1.09[1.02-1.18]$ & $0.96[0.91-1.02]$ & $1.01[0.96-1.06]$ \\
\hline Number of prescribed medications & $0.91[0.89-0.92]$ & $1.02[0.99-1.04]$ & $1.05[1.03-1.08]$ & $1.09[1.08-1.11]$ \\
\hline \multicolumn{5}{|l|}{ Laboratory results } \\
\hline Hemoglobin A1c >9 \% & $0.47[0.31-0.70]$ & $0.43[0.37-2.32]$ & $0.97[0.67-1.40]$ & $2.06[1.45-2.91]$ \\
\hline International normalized ratio $>3.5$ & $0.47[0.29-0.77]$ & $0.39[0.15-1.03]$ & $1.31[0.81-2.14]$ & $1.51[0.93-2.44]$ \\
\hline Substance use disorder & $0.41[0.27-0.64]$ & $0.93[0.46-1.86]$ & $1.14[0.74-1.77]$ & $1.90[1.32-2.73]$ \\
\hline \multicolumn{5}{|l|}{ Clinical encounters } \\
\hline Number of emergency department visits & $0.77[0.66-0.89]$ & $1.04[0.83-1.31]$ & $0.82[0.70-0.97]$ & $1.27[1.13-1.44]$ \\
\hline Number of hospitalizations & $1.09[0.91-1.31]$ & $0.56[0.40-0.83]$ & $0.83[0.66-1.06]$ & $0.99[0.85-1.16]$ \\
\hline \multicolumn{5}{|l|}{ Diagnoses } \\
\hline Bipolar disorder & $0.75[0.50-1.12]$ & $0.75[0.33-1.73]$ & $1.36[0.87-2.12]$ & $1.02[0.69-1.50]$ \\
\hline Alcohol-related & $0.64[0.49-0.83]$ & $1.17[0.72-1.93]$ & $1.33[1.02-1.75]$ & $1.37[0.99-1.88]$ \\
\hline Atrial fibrillation & $0.71[0.53-0.97]$ & $0.93[0.59-1.46]$ & $0.96[0.65-1.42]$ & $1.20[0.91-1.60]$ \\
\hline Diabetes & $0.51[0.41-0.64]$ & 0.89 [0.61-1.29] & $1.59[1.27-1.99]$ & $1.49[1.19-1.87]$ \\
\hline Post-traumatic stress disorder & $0.72[0.45-1.17]$ & $1.44[0.77-2.67]$ & $1.00[0.58-1.72]$ & $1.14[0.78-1.66]$ \\
\hline Psychosis & $0.76[0.55-1.05]$ & $0.53[0.28-1.00]$ & $1.09[0.77-1.53]$ & $1.38[0.99-1.92]$ \\
\hline Personality disorder & $0.62[0.33-1.18]$ & $1.56[0.68-3.58]$ & $0.54[0.25-1.17]$ & $1.54[0.83-2.85]$ \\
\hline Substance use disorder & $0.86[0.60-1.22]$ & $1.15[0.66-1.99]$ & $1.05[0.68-1.60]$ & $1.14[0.82-1.59]$ \\
\hline Depression & $0.71[0.62-0.82]$ & $1.01[0.80-1.28]$ & $1.05[0.88-1.26]$ & $1.54[1.32-1.80]$ \\
\hline Chronic pain & $0.53[0.38-0.74]$ & $0.79[0.45-1.38]$ & $0.80[0.56-1.15]$ & $1.87[1.43-2.45]$ \\
\hline Anxiety & $0.79[0.69-0.90]$ & $1.28[0.98-1.66]$ & $1.00[0.84-1.19]$ & $1.29[1.19-1.50]$ \\
\hline \multicolumn{5}{|l|}{ Medications (\%) } \\
\hline Benzodiazepines & $0.95[0.84-1.08]$ & $1.17[0.92-1.47]$ & $1.15[0.99-1.34]$ & $0.97[0.83-1.12]$ \\
\hline Opiates & $0.96[0.83-1.12]$ & $1.27[1.03-1.56]$ & $0.91[0.75-1.12]$ & $1.07[0.91-1.26]$ \\
\hline Selective serotonin reuptake inhibitors & $0.70[0.41-1.21]$ & $0.71[0.29-1.76]$ & $1.21[0.65-2.24]$ & $1.32[0.74-2.35]$ \\
\hline Antipsychotics & $0.89[0.19-4.15]$ & $1.26[0.22-7.36]$ & $2.00[0.73-5.44]$ & $0.76[0.20-2.86]$ \\
\hline Smoking cessation & $0.67[0.46-0.98]$ & $0.97[0.49-1.91]$ & $1.24[0.82-1.87]$ & $1.26[0.90-1.76]$ \\
\hline
\end{tabular}

*Based on census block group data

In summary, our study demonstrates that PCP's unique perspective on primary care team effort not only reflects the medical complexity of patients, but also accounts for behavioral health and socioeconomic factors impacting the level of effort required to care for patients. Current chronic disease-focused risk adjustment approaches often do not account for these unmeasured components of physician effort, increasing the potential for the unintended consequence that providers caring for patients with a greater number of psychosocial issues will not have sufficient resources to address patients' needs or receive adequate compensation for their work. ${ }^{47}$ Future studies should aim to improve understanding of primary care team effort and to develop approaches to better assess it. These will have important implications for 1) efficient resource allocation, 2) healthcare redesign that improves care and reduces physician burnout by providing the necessary support to PCPs in both visit-based and non-visitbased aspects of care, and 3) equitable physician compensation through improved risk adjustment approaches.

Funding: This study was funded by Partners Community Healthcare, Inc., and by the MGH Primary Care Operations Improvement Program. Dr. Hong was supported by a KL2/Catalyst Medical Research Investigator Training award from Harvard Catalyst, The Harvard Clinical and Translational Science Center (National Center for Research Resources and the National Center for Advancing Translational Sciences, National Institutes of Health Award KL2 TROO110O). The funding sources had no involvement in the collection, analysis, or interpretation of the data, or in the decision to submit the manuscript for publication.

The authors would like to thank Yuchiao Chang, $P h D$, for her help with statistical analysis. 
Corresponding Author: Andrew S. Hwang, MD MPH; Division of General Internal Medicine, Department of MedicineMassachusetts General Hospital, Gray Bigelow 730, 55 Fruit Street, Boston, MA 02114, USA (e-mail: ahwang1@partners.org).

\section{Compliance with Ethical Standards:}

Conflict of Interest: Dr. Clemens Hong is the Co-Founder of Anansi Health. Dr. Adrian Zai is the Chief Medical Informatics Officer of SRG Technology. All other authors declare no conflict of interest.

\section{REFERENCES}

1. Abrams M, Nuzum R, Mika S, Lawlor G. How the Affordable Care Act will strengthen primary care and benefit patients, providers, and payers. Issue Brief (Commonw Fund). 2011;1:1-28.

2. Blumenthal D, Abrams M, Nuzum R. The Affordable Care Act at 5 years. N Engl J Med. 2015;372(25):2451-8.

3. Ash AS, Ellis RP. Risk-adjusted payment and performance assessment for primary care. Med Care. 2012;50(8):643-53.

4. Goroll AH, Berenson RA, Schoenbaum SC, et al. Fundamental reform of payment for adult primary care: comprehensive payment for comprehensive care. J Gen Int Med. 2007;22:410-5.

5. Weir S, Aweh G, Clark RE. Case selection for a Medicaid chronic care management program. Health Care Financ Rev. 2008;30(1):61-74.

6. Freund T, Mahler C, Erler A, Gensichen J, Ose D, Szecsenyi J, PetersKlimm F. Identification of patients likely to benefit from care management programs. Am J Manag Care. 2011;17(5):345-52.

7. Ash AS, Zhao Y, Ellis RP, Schlein Kramer M. Finding future high-cost cases: comparing prior cost versus diagnosis-based methods. Health Serv Res. 2001;36(6 Pt 2):194-206.

8. Petersen LA, Pietz $\mathbf{K}$, Woodard LD, Byrne M. Comparison of the predictive validity of diagnosis-based risk adjusters for clinical outcomes. Med Care. 2005;43(1):61-7.

9. Ash AS, Ellis RP, Pope GC, et al. Using diagnoses to describe populations and predict costs. Health Care Financ Rev. 2000;21:7-28.

10. Ellis RP, Pope GC, Iezzoni LI, et al. Diagnosis-based risk adjustment for Medicare capitation payments. Health Care Financ Rev. 1996;17:101-28.

11. Kronick R, Gilmer T, Dreyfus T, Lee L. Improving health-based payment for Medicaid beneficiaries: CDPS. Health Care Financ Rev. 2000;21:29-64.

12. Safford MM, Allison JJ, Kiefe CI. Patient complexity: more than comorbidity. The vector model of complexity. J Gen Intern Med. 2007;22(Suppl 3):382-90.

13. Grant RW, Ashburner JM, Hong CS, Chang Y, Barry MJ, Atlas SJ. Defining patient complexity from the primary care physician's perspective: a cohort study. Ann Intern Med. 2011;155(12):797-804.

14. Hwang AS, Atlas SJ, Cronin P, Ashburner JM, Shah SJ, He W, Hong CS. Appointment "no-shows" are an independent predictor of subsequent quality of care and resource utilization outcomes. J Gen Intern Med. 2015.

15. Christianson JB, Zismer DK, White KM, Zeglin J. Exploring Alternative Approaches to Valuing Physician Services: A Report by Staff from the University of Minnesota. Washington: Division of Health Policy and Management for Medicare Payment Advisory Commission (Med PAC); 2011.

16. Bodenheimer T, Berenson RA, Rudolf $\mathbf{P}$. The primary care-specialty income gap: why it matters. Ann Intern Med. 2007;146(4):301-6.

17. Goodson JD. Unintended consequences of resource-based relative value scale reimbursement. JAMA. 2007;298(19):2308-10.

18. Jacobson $\mathbf{C J} \mathbf{J r}$, Bolon S, Elder N, et al. Temporal and subjective work demands in office-based patient care: an exploration of the dimensions of physician work intensity. Med Care. 2011;49(1):52-8.

19. Dyrbye LN, West CP, Burriss TC, Shanafelt TD. Providing primary care in the United States: the work no one sees. Arch Intern Med. 2012;172(18):1420-1.

20. Chen MA, Hollenberg JP, Michelen W, Peterson JC, Casalino LP. Patient care outside of office visits: a primary care physician time study. J Gen Intern Med. 2011;26(1):58-63.

21. Doerr E, Galpin $\mathbf{K}$, Jones-Taylor C, et al. Between-visit workload in primary care. J Gen Intern Med. 2010;25(12):1289-92.

22. Arndt B, Tuan WJ, White J, Schumacher J. Panel workload assessment in US primary care: accounting for non-face-to-face panel management activities. J Am Board Fam Med. 2014;27(4):530-7.

23. Petterson SM, Liaw WR, Tran C, Bazemore AW. Estimating the residency expansion required to avoid projected primary care physician shortages by 2035. Ann Fam Med. 2015;13(2):107-14.
24. Mainous AG 3rd, Ramsbottom-Lucier M, Rich EC. The role of clinical workload and satisfaction with workload in rural primary care physician retention. Arch Fam Med. 1994;3(9):787-92.

25. Wetterneck TB, Linzer M, McMurray JE, et al. Worklife and satisfaction of general internists. Arch Intern Med. 2002;162(6):649-56.

26. Bodenheimer T. Primary care-will it survive? N Engl J Med. 2006;355(9):861-4.

27. Schaufeli WB, Maassen GH, Bakker AB, Sixma HJ. Stability and change in burnout: a 10-year follow-up study among primary care physicians. J Occup Organ Psycho. 2011;84(2):248-67.

28. An PG, Rabatin JS, Manwell LB, Linzer M, Brown RL, Schwartz MD, MEMO Investigators. Burden of difficult encounters in primary care: data from the minimizing error, maximizing outcomes study. Arch Intern Med. 2009; 169(4):410-4.

29. Atlas SJ, Chang Y, Lasko TA, Chueh HC, Grant RW, Barry MJ. Is this "my" patient? Development and validation of a predictive model to link patients to primary care providers. J Gen Intern Med. 2006;2 1:973-8.

30. de Jonge P, Huyse FJ, Stiefel FC. Case and care complexity in the medically ill. Med Clin North Am. 2006;90:679-92.

31. Nalichowski R, Keogh D, Chueh HC, Murphy SN. Calculating the benefits of a Research Patient Data Repository. AMIA Annu Symp Proc. 2006: 1044. Ann Fam Med. 2014;12(6):573-6.

32. Hong CS, Atlas SJ, Ashburner JM, Chang Y, He W, Ferris TG, Grant RW. Evaluating a model to predict primary care physician-defined complexity in a large academic primary care practice-based research network. J Gen Intern Med. 2015;30(12):1741-7.

33. Bodenheimer T, Sinsky C. From triple to quadruple aim: care of the patient requires care of the provider. Ann Fam Med. 2014;12(6):573-6.

34. Hong CS, Siegel AL, Ferris TG. Caring for high-need, high-cost patients: what makes for a successful care management program? The Commonwealth Fund. 2014.

35. Garfield SR. The delivery of medical care. Perm J. 2006;10(2):46-56.

36. Gupta R, Bodenheimer T. How primary care practices can improve continuity of care. JAMA Intern Med. 2013;173(20):1885-6.

37. Reid MC, Engles-Horton LL, Weber MB, Kerns RD, Rogers EL, O'Connor PG. Use of opioid medications for chronic noncancer pain syndromes in primary care. J Gen Intern Med. 2002;17(3):173-9.

38. Chelminski PR, Ives TJ, Felix KM, et al. A primary care, multidisciplinary disease management program for opioid-treated patients with chronic non-cancer pain and a high burden of psychiatric comorbidity. BMC Health Serv Res. 2005;5(1):3.

39. Archer J, Bower P, Gilbody S, Lovell K, Richards D, Gask L, Dickens C, Coventry P. Collaborative care for depression and anxiety problems. Cochrane Database Syst Rev. 2012;10, CD006525.

40. Woltmann E, Grogan-Kaylor A, Perron B, Georges H, Kilbourne AM, Bauer MS. Comparative effectiveness of collaborative chronic care models for mental health conditions across primary, specialty, and behavioral health care settings: systematic review and meta-analysis. Am J Psychiatry. 2012;169(8):790-804.

41. WinkelmanR, Mehmud S. A Comparative Analysis of Claims-Based Tools for Health Risk Assessment. Society of Actuaries. April 20, 2007. http:// www.soa.org/Files/Research/Projects/risk-assessmentc.pdf. Accessibility verified June 2, 2015.

42. Rosen AK, Reid R, Broemeling AM, Rakovski CC. Applying a riskadjustment framework to primary care: can we improve on existing measures? Ann Fam Med. 2003;1(1):44-51.

43. Bodenheimer T, Berry-Millet R. Care management of patients with complex health care needs. Princeton: Robert Wood Johnson Foundation; 2009. December 2009. Research synthesis report 19.

44. Collins C, Hewson DL, Munger R, Wade T. Evolving Models of Behavioral Health Integration in Primary Care. New York, NY: Milbank Memorial Fund; 2010. Available at: www.milbank.org/ uploads/documents/10430EvolvingCare/10430EvolvingCare.html. Accessed May 8, 2015.

45. Ader J, Stille CJ, Keller D, Miller BF, Barr MS, Perrin JM. The medical home and integrated behavioral health: advancing the policy agenda. Pediatrics. 2015;135(5):909-17.

46. Zulman DM, Grant RW. Transforming care for complex patients: addressing interconnected medical, social, and behavioral challenges. J Gen Intern Med. 2016;31(3):263-4.

47. Hong CS, Atlas SJ, Chang Y, Subramanian SV, Ashburner JM, Barry MJ, Grant RW. Relationship between patient panel characteristics and primary care physician clinical performance rankings. JAMA. 2010;304(10):1107-13. 